\title{
Islamic Perspectives of Reproductive and Maternal Health: What Role Can Nigerian Muslim Religious Leaders Play in the Prevention of Maternal Mortality? -With Particular Reference to Zamfara State North- West Nigeria
}

Abdullahi Mohammed Maiwada ${ }^{1}$, Nik Mazlan Mamat ${ }^{1}$, Nor Azlina A Rahman ${ }^{1}$, Suzanah Abdul Rahman ${ }^{1}$, Tukur Mohammed Baba ${ }^{2}$.

${ }^{1}$ Kulliyyah of Allied Health Sciences International Islamic University Malaysia (IIUM), ${ }^{2}$ Department of Sociology, Usmanu Danfodiyo University, Sokoto, Nigeria .

\section{ABSTRACT}

Reproductive and Maternal health are an important components of public health and medicine which are concerned with the complete state of physical, mental and social wellbeing in all matters regarding reproductive system and health of mother especially during pregnancy.It implies ensuring that all women receive the care they need to be safe and healthy throughout pregnancy, childbirth and beyond. However, according to World Health Organization, millions of women all over the world do not have access to good quality health services during pregnancy and childbirth resulting in mortalities. Islam is a complete way of life. The Qur'an and Hadith consider pregnancy and child bearing as signs among other signs of the divine existence of Allah. The importance of maternal and reproductive is thus not unexplained in the Islamic perspectives. The study look at what role Muslim religious leaders can play in the prevention of maternal deaths and morbidities in developing countries. A qualitative study was conducted through in-depth interviews and focus groups discussion with a purposive sample of some Muslim religious leaders from Gusau local government area of Zamfara state northwest Nigeria in order to elicit information about the Islamic perspectives of reproductive and maternal health and the roles they can play in the prevention of maternal deaths among the Muslim communities. Muslim Religious leaders have a crucial role and contribution for the attainment and maintenance of good heath of women and children among Muslim communities through public enlightenment in the context of ' $i l m$ ', providing guidance through 'Fatwah' and community mobilization in the spirit brotherhood 'ukhuwah'. Islam does not accept the "preventable death of a woman" due to childbirth or pregnancy. Thus, Islam encourages attendance of antenatal care visits and health care seeking.

KEYWORDS: Islam, Muslim religious leaders, reproductive and maternal health, maternal mortality, Zamfara State, northern Nigeria.

\section{INTRODUCTION}

Humanity today is confronted by a major paradox: on the one hand, tremendous and unprecedented progress has been made in science, technology and knowledge in general, and the quality of life has improved vastly.Geographical distances that separate people have been overcome and communication is often instantaneous.In the medical sciences, as in engineering, manufacturing, agriculture, finance, international trade, education, etc., humanity continues to record progress. On the other hand, the gains of these developments have been unevenly distributed as vast segments of the 7.0 billion people that inhibit the earth are left behind in various conditions of economic, social, political and other forms of deprivation. In particular, global and regional social inequalities have meant that millions of people lag behind others by hundreds of years in terms of quality of

Abdullahi Mohammed Maiwada

Department of Biomedical Science,

Kulliyyah of Allied Health Sciences,

International Islamic University Malaysia (IIUM).

Kuantan Campus.

Email: ammaiwada@gmail.com life and opportunities for comfortable existence. Today, a globalised world is characterised by a very high quality of life for the top one fifth or $20 \%$ of humanity and the most primitive conditions for the lowest one fifth respectively, depending on where one lives. Disparities in access to health and opportunities for healthy living provide one such glaring illustration of the uneven distribution of the gains that humanity has made over the years. Vast numbers of people continue to grapple with basic problems that others have overcome and literally forgotten.

Analyses of religion have been a recurrent and lively issue in sociology, since the establishment of the discipline, in the $19^{\text {th }}$ Century, in its coherent form as we know it today. From inception, the founding fathers of the discipline such as Augustus Comte, Herbert Spencer, Emile Durkheim, Max Weber and Karl Marx had each tried to explore and explain the place of religion in relation to relationships between human beings. Even centuries before these western European thinkers, an earlier pioneer of sociological studies, Ibn Khaldun, the North African Arab scholar, historian, traveler and jurist, had been fascinated earliest pioneers of sociological studies 
by the place of religion in human society, especially in regard to its role in establishing the basis of solidarity or assabiyah, as he termed it, in human relations. $^{1}$

Ordinary definition of religion define it to mean an integrated and coherent system of beliefs and practices and conduct about humankind's physical and social universe, relating to the Supernatural, as an integrated system, and which also defines the relation humans, their existence and conduct, etc. to the central and defining notion or notions of the Supernatural. ${ }^{1}$

Religion is further characterised by a set of practices and rituals which unite adherents of such philosophies. It is deeply embedded in culture and provides the values, beliefs, norms, ideas, conduct, etc. that regulate the action and behaviour of human beings towards one another. ${ }^{2,3}$ As an illustration, the Five Pillars of Islam provides constitute a complete way of life they regulate the social and physical universe of human beings. Religion is major social institution. It is so important and critical that it forms one of the structural features holding society together with systems of economic production, political organisation and legal relations regarding law and order, education and skill acquisition, health and patterns of healthseeking behaviour. Religion serves to bond people into organised and coherent ,cooperating communities for the benefit of every member, and where the rights, responsibilities and privileges of individuals are clearly defined and respected provided each play their own part. ${ }^{1}$ In Islam for example, the concept of Ummah denotes a collectivity of people united by a common destiny and in which the welfare of the individual resides in the brotherhood of the community.

Here, inclusion and exclusion in terms of membership are clearly outlined and it is through adhering to the same and common principles of undertaking all activities. Religion is often a catalyst for change in socially and politically chaotic situations. A few examples will illustrate this point: The Religion of Islam was revealed at a time of great and widespread chaos and normlessness (Jahilliyah) which pervaded Arabian society; and which would later entrench law and social orderliness not only in the Arabian Peninsula but far beyond. ${ }^{2,3,4}$ While in Nigeria, the 1804 Jihad, led by Sheikh Usmanu Bn Fodiyo, that swept through Kasar Hausa- (most part of the today's northern Nigeria) was the answer to the need for the re-organisation of its disorderly and chaotic economy and society and which re-established order and unity among the people. $^{2,3,4}$ The 1804 Jihad, as we know brought about the establishment of the biggest, richest and most extensive heterogonous federating pre-colonial expire in Africa; and in his analyses of the transformation of $19^{\text {th }}$ century European society, the German scholar and thinker, Max Weber suggested that the principles of a doctrine of Christianity which emphasised sacrifice, investment, deferred consumption, salvation through the gratification hard work, ascetism, embodied in what he called the "Protestant Ethic" was responsible for the emergence and eventual dominance of the system capitalism, and which system also began to dominate other parts of the world. ${ }^{3,45,6}$

Annually there are more than 500,000 women who die from pregnancy and childbirth related complications and about $99 \%$ of them are in the in developing countries and additional 15-20 million women suffer debilitating consequences of pregnancy. 7,8 , and 9 While in a global context, Nigeria accounts for only about $2 \%$ of world population, but it accounts for about $10 \%$ of the global maternal deaths. $^{7,8,9,10}$ The death rate among women during childbirth in Zamfara State is alarming at about $1,025 / 100,000$ live births ${ }^{11,12,13,14}$ as compared to the national average of 576 according to the Nigeria Demographic Health Survey 2013. ${ }^{15}$ Health statistics indicate that five women die every day while 1,944 die annually., 15 In Nigeria, the utilization of maternal and reproductive health facilities by pregnant women during child delivery and antenatal care still remains a public health challenge this may be influenced by a lot of factors including demographic, socio-economic, cultural, religious, and obstetric and health system factors. ${ }^{16,12,13}$ Nigerian women deliver outside health facilities and without medically skilled attendants present or anyone. ${ }^{15,17}$ In Zamfara state the utilization of maternal and reproductive health care facilities and uptake is abysmally low with high preference for home delivery, antenatal care was $22.4 \%$ and hospital delivery was $5 \%$ and a total fertility rate of 7.5 and an uptake of contraceptives as low as $2 \%$ (contraceptive prevalence rate) according to NDHS 2013. $8,14,15 \& 16$

The aim of the study is to look at the role Muslim religious leaders can play in the prevention of maternal deaths and morbidities in developing countries with an emphasis of Zamfara State northwest Nigeria. Also the study reviewed the Islamic perspectives of maternal and reproductive health with a view to improve the maternal and reproductive health situation of mothers and women of reproductive age in Zamfara State, northwest Nigeria and developing countries in general as well as among the Muslim communities across the globe.

\section{MATERIALS AND METHODS}

\section{Study Area}

Zamfara state is one of the thirty six states that formed the Nigerian Federadation situated in the North-Western part of the country out of the six geopolitical zones of Nigeria. The state was established 20 years ago on the $1^{\text {st }}$ October, 1996 from the former Sokoto state. The state has a landmass area of about 38,418 Square kilometers. In terms of geography it is bounded in the North by Sokoto state and the Republic of Niger, in the West by Kebbi and Niger States, in the east by Katsina 
state and Kaduna state in the South. Zamfara State has a population of $3,259,846$ according to the 2006 census of the National population Commission ${ }^{18}$.

\section{Methodology}

Twelve northwest Nigerian Muslim religious leaders were interviewed using open ended questions and an interview guide through In-depth interviews. Also 6 focus group discussions (FGD) were also conducted for with a purposive identified Muslim Religious Leaders. All interviews were conducted in Hausa the local language that is the generally spoken language in the area. The interviews were recorded with a tape recorder and notes were taken during the conduct of both the In-depth interviews and FGD. These recorded interviews were then transcribe and translated into English for content analysis.

\section{RESULTS}

\section{Utilization and uptake of maternal and} reproductive health services:

The northwest Nigerian Muslim religious in Zamfara State are of the opinion that Muslim women should seek for health care especially during pregnancy or labour as of the saying that:

"Qayyid wa tawakka alal Lah" meaning "Do your best or prevent and believe or depend on Allah". During an in-depth interview one of the religious leaders cited an example of an Islamic country and how they care for the pregnant women and issues of reproductive health.

Also an Islamic scholar and northwest Nigerian Muslim religious leader, who is an Imam to one of the Jummaat mosques gave an example of their study tour trip to Egypt where he said they learnt that women's death in the health facility or at home as a result of delivery of pregnancy is an issue in that country.

"A maternal death audit is conducted on what causes the deaths unlike the case of Nigeria where the deaths of the woman is not considered an issue due to the fact the : women are not being taken care of especially by their husbands and immediate family members"

What Islam says or the Islamic view of Maternal and reproductive health:

In all their responses during IDIs and FGD the Muslim religious leaders were unanimous in their response about the Islamic saying, teaching and acceptance of maternal and reproductive health. In his observation during the FGDs one of the participants said:

"Shariah does not stop or prevent women from attending ANC or going to hospital neither did it prohibit a woman being attended to by an opposite sex (man) who is a professional to look after her and give her the medical care she requires".

Also another respondent opined that "It is Islamic for the woman to seek for care, have medical treatment and necessary care from the hospital or clinic. As the prophet (SAW) said "There is no disease without cure" - Ma anzallahu daan wa anzala maahu dawah" Hadith. Also during an IDI with another religious leader he cited another hadith of the prophet that:

"Also as narrated by Usamah bn Shareek: that I was with the prophet and he was asked by some Arabs" Oh the messenger of Allah should we take d medicines to cure diseases? The Prophet SWA said Oh yes servant of Allah, take medicines as Allah has not created any disease without creating a cure for it"-Hadith.

In his own interpretation also one of the respondents in the interviews mentioned that: "Islamic shariah does not condone the women to be in the state of ill health nor does it accept the situation where the woman or society to be sick especially the mother". Thus Shariah does not prevent a woman from going to the hospital or even delivering the child at the hospital. Preventive medicine was first in the early days of Islam when there was an outbreak in Medina during the Caliph Omar (RA) he directed that "those in the town not go out and those outside the city not to enter" which conform to the present day epidemiologic prevention methods. Also one of the Muslim religious leaders quote from the holy Quran that Allah SWA said"

"So hold that which I have given you and be of the grateful"- Quran 7:144. Therefore people wondered why anyone would not want to care for the pregnant women and allow for their preventable deaths.

\section{Barriers to utilization and uptake of $\mathrm{RH}$ and $\mathrm{MH}$} services

The Islamic religious leaders were asked on what they think are the barriers to the utilization and uptake of reproductive and maternal health services and they responded thus:

\section{On the health facilities and equipment}

They observed that there are no adequate health personnel and equipment in the Zamfara State and in most of the northern Nigerian states which leads to non-utilization or accessing of care by the women especially in the public health facilities. One them had this to say:

"The public health facilities in the state do have some qualified personnel but have no equipment. However the private health clinics have some equipment but no qualified health personnel"Focus Group Discussion

\section{On the Attitude of Health Workers}

Most of the respondents observed that there is a lot of negligence on the part of some of the health workers and they have bad attitudes towards the patients especially the ones from the rural areas 
and with low socio-economic class. Therefore it deprives women particularly the ones from the rural areas from accessing care due the attitude of the health personnel towards them. Other obstacles include waiting time at the hospital, and delay in being attended by the health workers. Also socioeconomic situation of the women also contributes to some of the factor contributing to access of healthcare by the women.

\section{Common reasons and causes of maternal deaths among pregnant women are:}

The participants in the FGD were different and observed that there are several and various reasons or causes of maternal death among pregnant women in their localities and it is attributed to "Delay of going to the hospital or seeking for care" according to one of the participants. While another respondent in an interview also said:

"Delay while in labour and prolonged labour without seeking medical attention or care" and "excessive bleeding" as some of the common causes of maternal deaths. They were all in agreement that: Coming late to the health facility "when it is too late-the woman almost dying or in a very bad condition" are among the reason for the deaths of the women during delivery or labour and they all stated that most of the women have a preferred home delivery and not want to deliver at the health facility. Socio-cultural issues are also some of the factors militating and contributing to maternal deaths. Other factors are institutional factors, lack of funding, corruption and nepotism.

\section{Other Issues}

Some of the other issues mentioned by the respondent and participants include 'out of pocket expenses' incurred by the family members, as was said by a respondent that "the immediate family or even relative including husband and in-laws scares away the women from delivering at the hospital" to avoid been talked about later as "One with bad luck" and that "she will be mocked by the members of the community and where she is in a polygamous family, the co-wives will code her as "one with bad luck"

Also another respondents said "For example before the woman is accepted for admission in the hospital before she delivers a baby she has to go through "routine bureaucratic hardships" at the health facility ranging from getting registered and before she is registered she has to pay- registration fees where she is given a hospital card, then she pays for admission fee before she is admitted into the labour ward then at the labour ward she has to provide some other admission materials such as dettol ( disinfectant), cotton wool, toilet paper (tissue) and gloves. And God forbids if she is to undergo an operational procedure may be CS (Caesarean Section), the story is entirely different as she pay double all the monies she paid from registration to admission and finally there are drugs or medicines that would be prescribed which she may need to take after the operation she also has to buy. That is why the Holy Quran see woman or mother as a very important to everybody as is said "She goes through hardship upon hardship......." (Quran-31: 11-14).

\section{DISCUSSIONS}

\section{Muslim Religious Leaders and Society}

Therefore, there is no doubt that perhaps more than anything else, religion will remain close to the heart of the people. Religious leaders will therefore remain important stakeholders in community affairs anywhere in the world. In our society today, Muslim religious leaders, have remained well established stakeholder in social life and will continue to play a very important role in the lives of individuals and in guiding the activities of communities. ${ }^{12,19}$ For the sake of analysis, some of the roles that the Muslim religious leaders play include: Directing the principles of social organisation, from which people draw individual values, aspirations and interests, draws heavily from the guidance and direction pointed out by the clergy. ${ }^{19,20}$ Being with the individual member of society from the cradle to the grave, directing affairs, pointing out the right and acceptable ways and conduct. In Islamic societies, the Muslim religious leaders welcomes the individual, at birth, as a new member of society recognised by all as they preside over the rites such as naming ceremonies; as one grows, the Muslim religious leaders plays an important role in socialising the new member into the ways of life of the society or what sociologists call the socialisation process - teaching and helping to inculcate values that will guide one to community life and what roles one is expected to play in life and what awaits one beyond. As the individual reaches maturity, the Muslim religious leaders officiate at rites to the formation of family; just as at death, the Muslim religious leaders presides over funeral ceremonies. $12,20,21,22$

In light of the foregoing therefore, it can be said without doubt that Muslim religious leaders have a definite role to play in promoting maternal health, as follows: The problems associated with maternal health affects the whole community for which reason it is part of the responsibility of the Muslim religious leaders in so far as it affects community welfare, and against which the people expect guidance and direction; As is known from several situation reports on the health status of children, future leaders and workers, is directly tied to the health status of their mothers. In spite of the documented immense contribution of the Islamic world to world civilisation and progress, Muslims are all too often wrongly seen as being hostile to innovations that would save lives or that improve the quality of life. Needless to say, such views are grossly wrongly and misleading. ${ }^{23}$

The fact is, for example, independent of mineral resource endowment; the Muslim-majority states of North Africa (Algeria, Egypt, Libya and Morocco) are 
far ahead of sub-Saharan countries in all indices of human development, especially relating to quality of life indices. The contention here is that the problems of maternal health emanate not from religion but other factors. In its many facets, Islam emphasises the concept of community, Brotherhood (Ukhwwaor Ummah)as a total context within which to undertake activities. The practice of congregational prayer is one of such injunctions and operates at least five levels, each of which encourages solidarity with other members of the Ummah. For example, prayer is an obligation on individuals but it is best offered in a congregationfirst at the level of the family, then neighbourhood, followed by another but weekly gathering for the Jummu'at prayer and finally an annual one, at the Eid prayer, or the biggest of them all, the Arafat, during Hajj for those who could afford to attend. The community levels are thus the household, neighbourhood, village, town, and city, etc.; in a larger gathering such as Eid Prayers. At each of these levels, the size of the congregation increases in size to involve ever more people in greater numbers, from a jam' $i$ to persons to millions during Arafat. At each level, the congregation forms a common community, not of individuals with differences from different backgrounds but as a community of worshippers. Quite a number of the people among the northern Nigerian Muslims continue to harbour suspicions about modern medical interventions even as these derive from divinely ordained knowledge-ilm against which there should be no room for doubts; as said by the Prophet (SAW)". Many cultural traits and especially those relating to the efficacy of modern medical innovations and interventions derive from local tradition and superstition and not from Islamic injunctions;

Other factors affecting the dismal state of maternal and reproductive health in our society today include not religion or Islam as was observed in $^{22,23}$ but relate to the following: corruption, in all its behemonic and overarching dimensions, including but not limited bribery, nepotism, primordialism, etc., a problem which perhaps lies at the heart of all others as listed here; general failure of governments at all levels to provide for the citizens through investments in economic development, provision of employment opportunities, limited job opportunities, idleness, poor business prospects, lack of capital and economic empowerment, etc., in short, it is the consequence of underdevelopment and which problems have tended to intensify competition for scarce resources and economic opportunities. ${ }^{5}$ Furthermore, there is widespread poverty, ignorance, illiteracy, etc., each of which tends to impose on their victims narrow worldviews, making people amenable to shallow and/or myopic and narrow minded interpretations of events and phenomena that they encounter and seeking for unorthodox solutions. Social changes in the sociocultural environment culminating in globalisation which threatens to swallow individuals in new values but they try to resist, re-affirming their core and unique identities. ${ }^{1,5}$ This suggests that as people encounter new ways, they resist because they feel alienated and threatened by these innovations as also indicated by. ${ }^{1}$ The tendency for the people especially in the northern part of Nigeria to resort to simplistic and/or in contextual interpretation of the Islamic Religious scriptures, and which tends to breed narrow-mindedness. The legacy of the past colonial masters, because the changes they sought to effect, the new modes of the organisation of life including education, governance, market-based social relation, in short all aspects of life of the community, sought first to denigrate and present indigenous society and its culture as "primitive", "uncivilised", belonging to the past, etc. Such an approach in turn alienated the people and generally tended to make them suspicious of "the ways of the whiteman", "modern innovations", etc., not least because the people saw that beyond the facade of a civilising mission of the colonialist, lay a clear attempt to re-orient society away from its traditional values so that it could more easily be stripped of its human and natural resource contents. $1,2,5 \notin 6$

Finally, attention is to be paid to the unique experience of the Muslim-majority areas and peoples in the Nigerian political economy, i.e. the remnant of the heart of the once mighty Sokoto Caliphate which included Zamfara state in northern Nigeria, West Africa where the people are often apprehensive of new innovations in health issues. The simple fact remains that the Muslim-majority areas have been the most poorly served by modern infrastructure like schools, health facilities, roads, etc. due to their low level of education, civic participation, poor governance and corruption as compared to other regions for instance the Southwest region which also has Muslim majority but with better indices and health indicators. ${ }^{4}$ It is also the people of those areas that have, in comparison with other parts of the country, more economically depressed least developed, and lags behind in almost every index of human development. ${ }^{24}$ It thus indicated that Muslimmajority communities continue to lag behind in all indices of maternal, neonatal and child health, as of all other measurements of human development ${ }^{24}$ cited NDHS 2008-8415 statistics which illustrate this point graphically, with regards to the availability of antenatal services (ANC) for pregnant women, against fertility rates and delivery attended by skilled personnel as follows:

$\begin{array}{lccc}\text { Zone ANC Availability } & \text { Fertility } & \text { RatesDelBySkPer* } \\ \text { North-West: } & 31 \% & 7.3 & 10 \% \\ \text { North-East } & 43 \% & 7.2 & 16 \% \\ \text { North-Central } & 65 \% & 5.4 & 43 \% \\ \text { South-South } & 70 \% & 4.7 & 56 \% \\ \text { South East } & 87 \% & 4.8 & 82 \% \\ \text { South-West } & 87 \% & 4.5 & 77 \% \\ \text { (*DelByPer = Delivery by Skilled } & \text { personnel) } & \text { NDHS } \\ \text { 2008 } & & & \end{array}$


The immediate implication of the above figures is that the areas that are most services deprived are the growing the fastest; that the problem could get worse because there will be more and more people competing for access to less and less services. The data above have been stagnant with little or no improvement compared to the 2003 NDHS and the current 2013 data. The north and Zamfara State figures are not farfetched from what was obtained in the figures above. ${ }^{15,26,27}$ What can be done by the Muslim Religious Leaders in Zamfara State? A lot as discussed below.

The Role for the Clergy-Muslim Religious Leader in the Mitigation of Maternal Health Problems and prevention of maternal deaths

No society, which expects to prosper in today's complex and globalised world, can continue to neglect or treat with levity, the issue of maternal, neonatal and children's health. This paper takes the position that conscious and sustained enlightenment and mobilisation must be embarked upon by our clergy to sensitise communities to the ills of the neglect of maternal and reproductive health. Admittedly, in terms of an agenda for the future, especially as these concerns a role for Islamic religious leaders, it is the case that all the problems of maternal identified above are but symptoms of a larger and deeper malaise affecting the Nigerian political economy as a whole. At work has been a far-reaching and insidious system decay, not just in the health sector but pervading through all major sectors including the economy, polity, family, educational institutions, the legal system, governance, the physical environment, etc. Inevitably, the resulting rot affects the fundamental value orientation of the citizenry at large. Unfortunately obscurantist solutions for health problems cannot substitute for concrete, evidencebased interventions, especially because if current trends are not arrested, the society is headed for a possible explosive future.

For maternal health what is perhaps needed is value re-orientation in the perception of disease, illness and health-seeking behaviour,a transformation process in which the Muslim Religious leaders-clergy has a definite role to play given the important role that this segment of the society plays ${ }^{28,29}$ as alluded to earlier and in the Holy Quran 5:32: "And if anyone saved a life, it would be as if he saved the life of the whole society".

\section{Recommendations}

By way of recommendations, it is proposed that the northwest Nigerian Muslim religious should: i). Be agents for social change and societal transformation such that our people begin to accept scientific innovations and inventions with which to improve the quality of their lives, once these do not impinge on the fundamental principles of the Islamic religion. Research has shown that most of the people need only a little "push" in the right direction. The success recorded in getting pregnant women to accept and access antenatal clinic services is a good example, as has been the efforts to overcome resistance to immunisation services. In sermons, the northwest Nigerian Muslim religious can and should extort people to take better care of themselves and their families. Household heads should be reminded about their responsibilities for the welfare of the members of their families. ii). Embark on enlightenment and mobilisation, helping the congregation to distinguish between substance and shadow in problems of maternal health or other harmful practices and matters relating to welfare issues for that matter. Matters of maternal health needs to be consciously incorporated into themes of sermons and preaching activities in simple, comprehensible and unambiguous language for consumption of the old, young, males and females, etc. In view of the urgency of the situation, these roles and responsibility must be discharged with passion but based on integrity and exemplary behaviour. iii).reorienting the people away from being held to ransom by delusions and superstition and looking towards the future with hope rather than despair, helplessness and despondency; empowering the people towards self-determination and self-respect, personal dignity and self-reliance; Encouraging their congregations to realise and accept the efficacy of modern interventions in health care especially maternal and reproductive health based on knowledge- ilm that that have been divinely provided to help humankind. Also the Muslim religious in Zamfara State and other northern Nigerian States needs to collaborate and work in conjunction with other elites and professionals in enlightening their subject and bringing development to their region in order to change the poor maternal and child health indices in the states of northern Nigeria and Zamfara in particular.

\section{CONCLUSION}

The Muslim religious leaders have always been an integral part of communities for centuries. A turning point was encountered when colonialists sought to divest governance from community affairs, relegating members of the Muslim religious to ceremonies, away from leadership responsibilities. This was for the obvious reason that the colonialists were determined to destroy those aspects of our culture which were known to harbour the potential to challenge colonial rule. The colonialist thus sought to isolate the Muslim religious so as to blunt the revolutionary zeal and determination of its members. In turn, the Muslim religious leaders, retreated in relevance but continued to remain influential at the level of communities. It was not surrender. Rather, it was a strategic retreat into local relevance, even if unconsciously so. Today, the Muslim religious is and should be out in force, reaffirming the bonds that continue to not only hold society together but to transform it in the light of modern realities. As 
earlier alluded to, responsibility for the welfare of the community is not new to the Muslim religious. It is deeply entrenched in the tenets of Islam. There are enough injunctions in the Qur'an and the Hadith to support this contention. The state of maternal health have serious implications for the society, lives continue to be wasted because women lack access to health facilities as few as the latter may be. From the foregoing, it may be concluded that the need to confront the problem is indeed necessity-dharurat. This paper agrees with the view that the Muslim Religious leaders have a role, and indeed a duty, to guide the people towards a completely fresh perspective which suggests that the problems associated with maternal mortality and morbidity are social and, therefore, preventable and surmountable from the Islamic perspectives and no woman should die as result of giving birth or delivery as was attested to by majority of the Muslim religious that participated in this study and even in other similar studies.

\section{ETHICAL APPROVAL AND CONSIDERATION FOR THE STUDY}

The ethical approval were sought for and study protocol was submitted to The Zamfara State Health Research and Ethics committee for their review and consideration and the approval was obtained, also the approval of the IIUM Kulliyah of Allied Health Sciences Research and ethics committee was obtained before the conduct of the research. Permission of the relevant agencies and gatekeepers were sought at all levels, while the verbal informed consent of all respondents was gotten before the conduct any of the interviews.

\section{ACKNOWLEDGEMENT}

The authors wish to acknowledge the support of Zamfara State Ministry of Health officials and the Muslim religious leaders who participated in this study for their time and cooperation.

\section{REFERENCES}

1. Vago, Steven. 1999. Social change, Upper Saddle River, New Jersey, Fourth Edition.

2. Usman, Yusuf B. 2006. The Sokoto Caliphate and nation building, in Bobboi, $\mathrm{H}$ and Yakubu, A.M., eds., The Sokoto caliphate - History and Legacies, 1804-2004, Volume 2, Kaduna, Nigeria: Arewa House, pages 149 - 158.

3. Mudasiru S. Eds. Abdul Razak Al-Aidrus M.A. Sokoto (2013). Caliphate: Its Rise and Fall. International Institute of Islamic Thought and Civilization (ISTAC), International Islamic University Malaysia (IIUM). Kuala Lumpur, Malaysia.

4. Chafe K. S., Zamfara State: Its History, Challenges and Prospects in the Nigerian Federation. Public Lecture at the $20^{\text {th }}$ Anniversary of the Creation of Zamfara State. $1^{\text {st }}$ October, 2016

5. Bach, Daniel C. 2001. "Inching towards a country without a state: Prebendalism, violence and state betrayal in Nigeria", in C. Clapham, J. Herbst and G. Mills, eds., Big African States, Johannesburg: Wits University Press, Pp. 63 -96.

6. Watts, Mike.1983. Silent violence - Food, famine and peasantry in Northern Nigeria, Berkeley, CA, University of California Press.

7. World Health Organization (WHO). 2014. Trends in maternal mortality: 1990 to 2013 Estimates by WHO, UNICEF, UNFPA, The World

9. World Health Organization (WHO).1999. Reduc tion of Maternal Mortality: A joint WHO/UNFPA/UNICEF/WORLD BANK STATEMENT 22. World Health Organization (WHO). 2010. Trends in maternal mortality: 1990 to 2008 Estimates by WHO, UNICEF, UNFPA, The World Bank and the United Nations Population Divi sion (9241507225).

10. Nigeria demographic and health survey 2008: Calverton, Maryland: National Population Com mission and ORC Macro.

11. Adamu, Y. M., Salihu, H. M., Sathiakumar, N., \& Alexander, G. R. 2003. Maternal mortality in Northern Nigeria: a population-based study. Eu ropean Journal of Obstetrics \& Gynecology and Reproductive Biology, 109(2), 153-159.

12. Audu, B.M., Takai, U.I. and Bukar, M., 2010. Trends in maternal mortality at University of Maiduguri teaching hospital, Maiduguri, NigeriaA five year review. Nigerian Medical Journal, 51(4), p.147.

13. Zamfara State Government. 2014. Health Sector Medium Term Sector Strategy 2014 - 2016

14. Maiwada,A.M., Rahman, N. A. A., Abdul Rahman S, Mamat N M \& Tukur A.B. 2015. Intervention Programmes and Policies for Maternal Mortality Reduction in Zamfara State, Northwest, Nigeria: A Review 2005-2015. Intl Journal of Advanced Research in Social Engineering and Development Strategies. 3(1)157-173

15. Nigeria demographic and health survey 2013: Calverton, Maryland: National Population Commission and ORC Macro.

16. Doctor, H. V., Findley, S. E., \& Afenyadu, G. Y. 2012. Estimating maternal mortality level in rural northern Nigeria by the sisterhood method. International Journal of Population Research, doi:10.1155/2012/464657

17. Ismail T, Cheekhoon, C., Tinsu, T., Tukur M.B., Munir'deen Al. Why Women are Averse to Facility Delivery in Northwest Nigeria: A Qualitative Inquiry. 2016. Iran JPub Health 45(5); 586-595

18. National Population Commission. Nigeria National Population Census 2006.Federal Government, Federal Republic of Nigeria, Abuja FCT

19. Underwood C. Islamic Precepts and family planning: The Perception of Jordanian Religious Leaders and Their Constituents. Intl Fam Planning Persp, 2000, 26(3):110-117

20. Freij, L.S. ,2009. Muslim religious leaders as partners in fostering positive reproductive 
health and family planning behaviors in Yemen:

A best practice. Washington, DC: USAID

21. Wan Hassan WZ, Alias J, Muslim. N, Yunos N, Umar A. Role of Fatwa a Medium for Information Dissemination in TacklingMuslim Community's Religious Issues in Terengganu. Middle- East J. Sci.Res., 22(3): 470-477, 2014

22. Al-Mujtaba M., Cornelius L.J., Galadanchi H., Erekaha S., Okundaye J.n., Adeyemi A.O., SamAudu .A.2016. Evaluating Religious Influences on utilization of maternal health services among Muslim and Christian Women in North-Centeral Nigeria.. BioMed Research International. Hindawi Publising Corporation. ID 3645415

23. Ganle, J.K., 2015. Why Muslim women in Northern Ghana do not use skilled maternal healthcare services at health facilities: a qualitative study. BMC international health and human rights, 15(1), p.10.

24. United Nations Development Programme (UNDP). 2009. Human development report, 2008 (Nigeria), Abuja, UNDP.

25. Mairiga, A.G., Kyari, O., Kullima, A. and Abdullahi, H., 2007. Knowledge, Perceptions and Attitudes of Islamic Scholars towards Reproductive Health Programs in Borno State, Nigeria. African journal of reproductive health, pp.98-106.

26. Demographic, N., 2003. Health survey (NDHS). National Population Commission, ORC Macro, Calverton, Maryland, USA, pp.151-4.

27. Ononokpono, Dorothy Ngozi, Clifford Obby Odimegwu, Eunice Imasiku, and Sunday Adedini. "Contextual determinants of maternal health care service utilization in Nigeria." Women \& health 53, no. 7 (2013): 647-668

28. Walton, L.M., Akram, F. and Hossain, F., 2014. Health Beliefs of Muslim Women and Implications for Health Care Providers.

29. Maiwada, AM, Rahman, N. A. A., Abdul Rahman S, Mamat N M and Ann-Walker J.2016. The Islamic Religious Leaders as Health Promoters: Improving Maternal Health in Selected Communities of Zamfara State, Nigeria. Journal of Reprod and Infert 7 (1): 08-14. 